Revista Tecné, Episteme y Didaxis: TED. Año 2014, Número Extraordinario. ISSN Impreso: 0121-3814, ISSN web: 2323-0126

Memorias, Sexto Congreso Internacional sobre Formación de Profesores de Ciencias. 08 al 10 de octubre de 2014, Bogotá

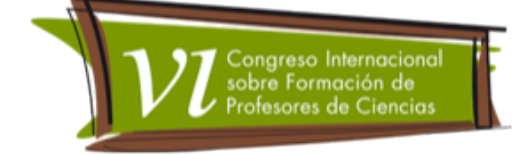

\title{
O Projeto 30 e a reforma curricular da Química na Argentina (1970-1978)
}

Bruno Ferreira dos Santos'

Categoria 2. Trabalho de investigação

\section{Resumo}

Neste trabalho investigamos a história do Projeto 30 para a reforma curricular da química escolar na Argentina durante a década de 1970 e suas ações de capacitação e aperfeiçoamento docente. Procuramos compreender como foi possível a sua permanência e continuidade ao longo de diferentes governos e as origens e marcas de sua particular configuração, a qual envolvia cientistas, professores universitários, burocratas do aparato estatal de educação e organizações multilaterais e filantrópicas. Os discursos em prol da modernização da educação científica incorporavam elementos de cientificidade e tecnocracia como fundamentais para o progresso social e econômico. A formação de professores passa a ser vista como problemática e origem de muitos problemas para o ensino de química e os professores necessitam se aperfeiçoar e modernizar os seus métodos e conteúdos.

\section{Palavras chave}

Formação continuada, ensino de química, reforma curricular

\section{Objetivos}

Entre as décadas de 1960 e 1970 na Argentina, foram desenvolvidos alguns projetos de reforma curricular com o objetivo principal de transformar o ensino escolar das ciências naturais. Esses projetos foram acompanhados por cursos de capacitação e de formação continuada para os docentes em exercício, os quais eram apresentados aos novos conteúdos e métodos para o ensino que essa reforma buscava implementar. Dita reforma e os cursos que a acompanham ocorreram no marco de uma configuração inédita no cenário argentino, que uniu cientistas e burocratas do aparato estatal vinculado à educação, e o patrocínio financeiro de instituições multilaterais e filantrópicas, como a UNESCO e

'Departamento de Química e Exatas, Universidade Estadual do Sudoeste da Bahia. Email: bf-santos@vol.com.br 
Revista Tecné, Episteme y Didaxis: TED. Año 2014, Número Extraordinario. ISSN Impreso: 0121-3814, ISSN web: 2323-0126

Memorias, Sexto Congreso Internacional sobre Formación de Profesores de Ciencias. 08 al 10 de octubre de 2014, Bogotá

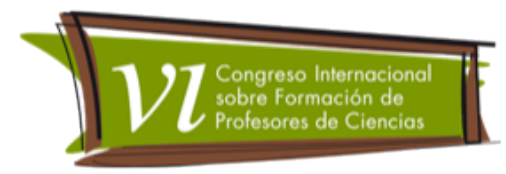

a Fundação Ford. Para a reforma do currículo da Química e a capacitação docente foi criado um projeto no âmbito do INEC, o Instituto Nacional para el Mejoramiento de la Enseñanza de las Ciencias, em 1970. O Projeto 30, como ficou nacionalmente conhecido, desenvolveu-se durante quase toda essa década, atravessando governos de matizes ideológicas muito distintas. Compreender como este projeto apresentou semelhante continuidade em um momento tão conturbado da história argentina ainda é uma tarefa pendente. Neste trabalho, apresentamos o Projeto 30 como um empreendimento de capacitação docente de largo alcance, buscando averiguar, em sua conformação e desenvolvimento, aquelas características que o permitiram atravessar este período de modo contínuo e estável, e também quais reflexos originados na particular associação entre cientistas e burocratas podem ser observados na configuração do mesmo.

\section{Marco teórico}

Quando nos aproximamos de um objeto histórico com o interesse de transformálo em um objeto de pesquisa no âmbito da educação, devemos observar, além das ideias e doutrinas pedagógicas vigentes na época histórica sob estudo, os contextos sociais e culturais mais amplos em que essas ideias surgem, ganham força, se disseminam e adquirem autonomia. A diversificação das fontes (documentos, livros didáticos, programas escolares, entrevistas) ajuda a compor o panorama, com suas permanências e rupturas, que tentamos decifrar. No caso deste objeto em questão, um projeto de formação continuada para professores de química, originado e conduzido por um organismo ligado ao aparato estatal, procuramos observar, com o ânimo de compreender a extensão, o alcance e as características do mesmo, os discursos e as práticas ao redor da ciência que despertaram o interesse de cientistas a se envolverem com o currículo escolar. No campo educacional também confluíram discursos e práticas que potencializaram a associação entre cientistas, burocratas e instituições multilaterais e filantrópicas e contribuíram para a configuração particular do Projeto 30.

\section{Metodologia}

Os métodos e técnicas da pesquisa histórica em educação aplicados nessa pesquisa incluíram a pesquisa em arquivos, a leitura, a classificação e a interpretação de fontes primárias e secundárias para a reconstrução dos processos históricos. Os documentos pesquisados como fontes primárias abrangeram atas de congressos e conferências internacionais e nacionais, disposições e regulamentos de Ministérios e órgãos responsáveis pela educação escolar, programas, projetos e planos de estudo para a formação de professores. 
Revista Tecné, Episteme y Didaxis: TED. Año 2014, Número Extraordinario. ISSN Impreso: 0121-3814, ISSN web: 2323-0126

Memorias, Sexto Congreso Internacional sobre Formación de Profesores de Ciencias. 08 al 10 de octubre de 2014, Bogotá

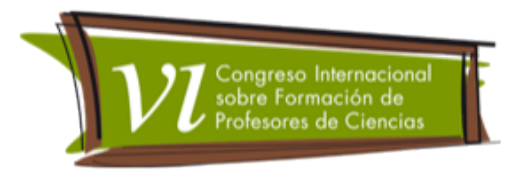

Os testemunhos orais obtidos de informantes chaves ajudaram a reconstruir passos e etapas do Projeto 30. Os livros didáticos de química foram utilizados como fontes secundárias nesta pesquisa.

Os documentos não foram analisados como fontes de dados extraídos de seu contexto, mas vistos como evidências materiais de processos sociais. A pesquisa enfatizou as relações entre as produções discursivas e as práticas sociais sem desconhecer a existência de duas lógicas heterogêneas: "a que organiza a produção e a interpretação dos enunciados e a que rege as ações e as condutas" (CHARTIER, 1997 apud ROCKWELL, 2009, p. 166).

\section{Resultados}

Na Argentina, entre os anos 1950 e 1960, o Estado investe na institucionalização da ciência por meio da criação do CONICET, o conselho nacional de promoção da ciência e tecnologia, acompanhando diretrizes e doutrinas sobre o progresso econômico e social pressupostas pela então em voga teoria do desenvolvimento. Os modelos das instituições que impulsionavam o progresso eram oferecidos pelos países desenvolvidos, e cabia aos menos desenvolvidos, de acordo com essa teoria, importar capitais financeiros e culturais, para emular o seu próprio desenvolvimento. Por outro lado, a teoria do capital humano, disseminada por meio de organizações multilaterais como a UNESCO e a OEA, associa fortemente o desenvolvimento econômico com a educação. A expansão do ensino secundário na Argentina, fenômeno observado especialmente a partir dos anos 1950, vem acompanhada de ideias, no campo pedagógico, de planificação e modernização. O currículo escolar é visto como obsoleto e defasado em relação ao espetacular desenvolvimento das ciências pós-guerra. As notícias sobre reformas curriculares nos Estados Unidos e Inglaterra circulam por meio de grandes conferências sobre a educação que ocorrem na América Latina.

Neste contexto, discursos originados em diferentes âmbitos buscam estabelecer consensos ao redor do papel e da importância da educação científica para a sociedade. Desde os primeiros cursos de capacitação docente ofertados pelo CONICET durante os anos 1960, que tinham como objetivo, entre outros, proporcionar aos estudantes "uma sólida formação científica básica e o fomento às vocações para o estudo e a investigação das disciplinas científicas" (Argentina, 1967), aos grandes planos de desenvolvimento produzidos pelo governo central que buscavam reorientar a formação de recursos humanos de nível universitário: 
Revista Tecné, Episteme y Didaxis: TED. Año 2014, Número Extraordinario. ISSN Impreso: 0121-3814, ISSN web: 2323-0126

Memorias, Sexto Congreso Internacional sobre Formación de Profesores de Ciencias. 08 al 10 de octubre de 2014, Bogotá

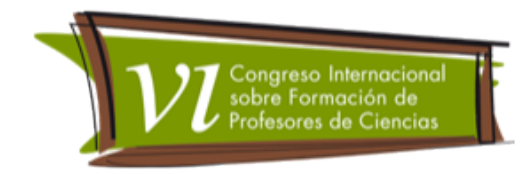

(...) el orden probable de prioridades en cualquier acción futura concierne a la política de recursos humanos en el área del personal científico y tecnológico sería: 1) Agrónomos; 2) Científicos puros; 3) Ingenieros (Argentina, 1968, p. 134).

Observamos a preocupação com o fortalecimento da presença das ciências na sociedade argentina. Os discursos sobre a reforma curricular das ciências naturais dos anos 1960 e 1970 destacam o papel central do professor para o êxito deste empreendimento:

Cabe observar que los congresos y seminarios, tanto nacionales como internacionales, las encuestas entre instituciones y docentes y aún las consideraciones fundamentales que acompañan a todo proyecto de reforma, reconocen explícitamente que todos los problemas, tanto teóricos como prácticos, que plantea la enseñanza de las ciencias, giran alrededor de la calidad de la formación y de la situación de los docentes (ARGENTINA, 1978, p. 1).

Será esse destaque e esse reconhecimento o propulsor de toda uma série de cursos de atualização e aperfeiçoamento docente que foram desenvolvidos nessas duas décadas. Os professores contemplados nessas iniciativas eram convocados a atuarem como agentes líderes e multiplicadores, disseminando as inovações e as mudanças que a reforma desejava implementar no ensino de ciências.

O Projeto 30 teve como antecedente os cursos de capacitação oferecidos pelo CONICET, por meio de seu recém-criado Departamento para o Ensino de Ciências, durante os anos 1960, a maioria destes ofertada como cursos de verão. Estes cursos iniciaram a lógica da multiplicação, pela qual os professores eram selecionados em obediência a critérios como localização geográfica de sua atuação profissional, de modo a espalhar pelo país os novos e modernos conteúdos e métodos de ensino para as diferentes ciências e matemática (Errasmupe, 2013). Paralelamente aos cursos oferecidos pelo CONICET, diversas conferências internacionais e nacionais ocorrem durante toda a década, culminando com a I Conferência Interamericana sobre o Ensino de Química (CIEQ), a qual tem lugar na cidade de Buenos Aires em 1965. Nela participam professores universitários de todo a América Latina, mas também da Inglaterra e dos Estados Unidos. Entre as diversas recomendações dessa conferência encontra-se a atualização dos conteúdos e métodos de ensino da química como 
Revista Tecné, Episteme y Didaxis: TED. Año 2014, Número Extraordinario. ISSN Impreso: 0121-3814, ISSN web: 2323-0126

Memorias, Sexto Congreso Internacional sobre Formación de Profesores de Ciencias. 08 al 10 de octubre de 2014, Bogotá

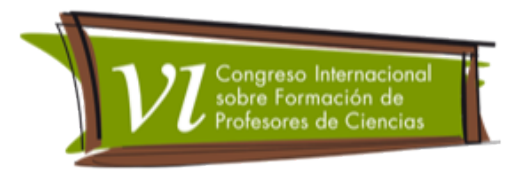

uma tarefa urgente a ser cumprida, por meio, principalmente, de cursos de capacitação e atualização dos docentes.

Com a criação do INEC em 1967, com recursos da Fundação Ford, o CONICET busca, com esse novo organismo, garantir a continuidade de suas ações de capacitação docente, cumprindo, entretanto, as mesmas funções que já realizavam o seu Departamento para o Ensino de Ciências. Este Instituto será estabelecido por meio de um convênio entre o Conselho científico e a Secretaria de Estado de Cultura e Educação, porém suas ações serão limitadas ao ensino médio. Durante toda a sua existência, O INEC será a referência argentina para o ensino de ciências e, como tal, manterá relações com organismos estrangeiros similares. Em 1969 o INEC organiza, com o patrocínio da OEA, em Buenos Aires o Primeiro Curso Latino americano para a atualização e o aperfeiçoamento docente em química. No ano seguinte na província de San Luís, o INEC promove o Primeiro Colóquio Nacional sobre o ensino de química, durante o qual os professores participantes entram em contato com o material desenvolvido e trabalhado no curso anterior promovido pela OEA. Neste mesmo ano é firmado um convênio entre o INEC e a ANEMS - Administração Nacional para o Ensino Médio e Superior, o qual resultará no Projeto 30, inspirado na experiência do curso latino americano. Este projeto iniciará suas atividades de modo experimental, em algumas unidades escolares do país dependentes da ANEMS. Em seu primeiro ano, somente 20 professores participaram de suas atividades.

O curso de aperfeiçoamento docente desenvolvido pelo Projeto 30 incluía 60 horas de aulas teóricas, reunindo um programa que abrangia a química geral, a química inorgânica, a química orgânica, a físico-química e noções de química biológica, além de 150 horas de práticas de ensino em laboratório e 100 horas de metodologia e problemas conceituais e numéricos. A avaliação do projeto, a cargo do próprio INEC, constituía numa prova de rendimento respondida pelos alunos, a qual indicava os avanços no processo de ensino e aprendizagem, além de um questionário de opinião respondido pelos professores sobre o desenvolvimento do Projeto. Um rigoroso tratamento estatístico era empregado na estimação dos resultados dessa avaliação.

Entre 1970 e 1978, diversas disposições e resoluções autorizam a continuidade e a expansão do Projeto a outros estabelecimentos escolares. Na configuração do Projeto 30, professores universitários da área de química do INEC estavam a cargo da organização e da implementação dos cursos, enquanto a ANEMS convocava as escolas e os professores participantes. O INEC também conduzia as avaliações e divulgava seus resultados. A OEA, por meio de seu Departamento de Assuntos 
Revista Tecné, Episteme y Didaxis: TED. Año 2014, Número Extraordinario. ISSN Impreso: 0121-3814, ISSN web: 2323-0126

Memorias, Sexto Congreso Internacional sobre Formación de Profesores de Ciencias. 08 al 10 de octubre de 2014, Bogotá

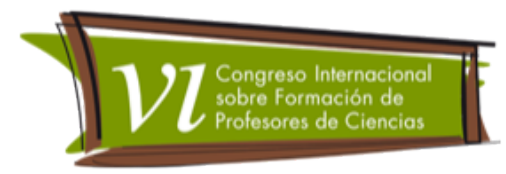

Educativos, custeava grande parte das atividades do Projeto 30. Em 1978, após quase uma década de aplicação, o Departamento de Ensino Médio emite um parecer atestando que os conteúdos do Projeto 30 coincidem com aqueles recomendados por todos os congressos internacionais sobre o ensino de química (Argentina, 1978b) e o Ministério da Cultura e Educação publica os novos planos de estudo para a química no ensino médio neste mesmo ano, repetindo os mesmos blocos de temas do curso latino americano oferecido em 1970 (Santos, 2012). O Projeto 30 passará a ser referência para os autores de livros didáticos, que o citam de modo a angariar legitimidade junto aos docentes, como a popular coleção de química de Héctor Sirventi (Santos, 2011). Entretanto, toda essa reforma e movimentos ao redor do docente de química parecem influenciar muito pouco a formação inicial: o Instituto Joaquín González, instituição tradicional e referente para a formação de professores na Argentina, modifica seu plano de estudos em 1971, e somente o alterará novamente em 2004/5. Neste plano de 1971 percebe-se, em relação ao anterior de 1963, a introdução da psicologia genética de Piaget em disciplinas como "Psicologia Evolutiva y Educacional" e "Conducción del aprendizaje" subsistuindo as antigas "Psicologia educacional y técnicas de investigación" y "Psicología de la adolescencia", e uma importância maior da experimentação para o ensino de química, observada na recém criada disciplina "Experimentación escolar y trabajos de taller".

\section{Conclusões}

Discursos que buscam fortalecer a presença da ciência na sociedade unem os esforços de cientistas, professores universitários, burocratas do aparato estatal da educação e organizações multilaterais e filantrópicas em torno de uma reforma curricular para o ensino escolar das disciplinas de ciências naturais. O Projeto 30 para o ensino de química é fruto desse esforço que atravessa duas décadas e representa um passo a mais em direção à internacionalização do currículo escolar. O professor entra em cena como uma das principais fontes dos problemas representados nos discursos sobre o ensino escolar de ciências e, portanto, alvo predileto das ações e iniciativas dos reformadores. Incorporando as noções de modernização veiculadas desde os anos 1960, as quais perpassam uma abordagem "científica" da realidade social, o Projeto 30 adquire legitimidade frente à comunidade de educadores químicos, transformando o panorama do ensino dessa ciência e cumprindo seus objetivos principais ao fim da década de 1970. Sua particular configuração, organizada pelo INEC, instituição em que colaboravam cientistas e burocratas, o financiamento externo e esse caráter científico, representado pelas constantes avaliações estatísticas 
Revista Tecné, Episteme y Didaxis: TED. Año 2014, Número

Extraordinario. ISSN Impreso: 0121-3814, ISSN web: 2323-0126

Memorias, Sexto Congreso Internacional sobre Formación de

Profesores de Ciencias. 08 al 10 de octubre de 2014, Bogotá

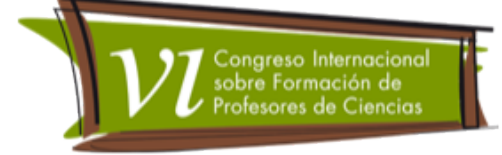

desenvolvidas por seus implementadores, contribuem para a sua continuidade ao longo dos diferentes governos que conduzem a Argentina.

\section{Referências bibliográficas}

Argentina. (1967). Antecedentes y áreas de actividades del I.N.E.C. Buenos Aires: Secretaría de Estado de Cultura y Educación.

Argentina. (1968). Educación, recursos humanos y desarrollo económico-social. Tomo II. Buenos Aires: Secretaría de Consejo Nacional de Desarrollo.

Argentina. (1978a). Evaluación del proyecto de actualización de la enseñanza de la química Proyecto 30. Programa Regional de Desarrollo Educativo.

Argentina. (1978b). Resolução no. 606. Boletin de comunicaciones no. 49. Buenos Aires: Ministerio de Cultura y Educación.

Erramuspe, J. (2013). Innovación y reforma en la capacitación de docentes para la enseñanza de las ciencias en el período modernizador: El caso del INEC. Tesis de Maestría. Universidad Nacional de Luján, Argentina.

Rockwell, E. (2009). La experiencia etnográfica: Historia y cultura em los procesos educativos. Buenos Aires: Paidós.

Santos, B.F. (2011). Reforma curricular no ensino escolar de química: Um estudo sociohistórico do caso argentino (1956-1983) [DVD]. Anais do VIII ENPEC, Campinas.

Santos, B.F. (2012). The Sputnik reaches Argentina: The curricular reform in chemistry teaching (1956-1983). In Bruguiére, C.; Tiberghien, A. \& Clément, P. (org). Proceedings of the ESERA 2011 Conference: science learning and citizenship. Acedido em 21/04/2014 em http://www.esera.org/publications/esera-conference-proceedings/sciencelearning-and-citizenship/ 